\title{
PEMBERIAN PUPUK ORGANIK SUPER NATURAL NUTRITION (SNN) PADA TANAMAN SELADA ( Lactuca sativa,L ) DI TANAH ULTISOL
}

\author{
The Extention Of Super Natural Nutrition ( SNN ) The Organic Fertilizer \\ To Lettuce ( Lactuca sativa, L ) at Ultisol Soil \\ Surtinah \\ Fakultas Pertanian Unilak Pekanbaru
}

\begin{abstract}
The purpose of this research was done by using completely the randomized design of cunstruction which consist of six treatments with three replications, such as : control, SNN 0,5 cc/l; SNN cc/l; SNN 1,5 cc/l; SNN 2 $c c / l$; and $S N N 2,5 \mathrm{cc} / l$. The parameter that we search are from the heigt of the plant, the count of the leaf, the length of the leaf and the fresh weight of the plant it self. The data which analyses is used Polynomial regression. The results showed that, the concentrate of SNN that given the hights product of lettuce is 2.5 cc / l of water.
\end{abstract}

Key words: Organic Fertilizer, Super Natural Nutrition, Completely randomized design,polynomial regression.

\section{PENDAHULUAN}

Tanaman selada ( Lactuca sativa,L ), merupakan tanaman sayuran yang banyak dibudidayakan di Pekanbaru, namun produksi di Kota ini tidak setinggi produksi selada yang berasal dari Kota lain. Hal ini antara lain disebabkan oleh kondisi tanah daerah ini didominasi oleh tanah Ultisol yang mengandung sedikit unsur hara, permeabelitas rendah, $\mathrm{pH}$ rendah, dan bahan organik tanah juga rendah. Sedangkan tanaman selada untuk berproduksi maksimal menghendaki tanah yang subur, gembur, banyak mengandung humus dengan $\mathrm{pH} \mathrm{6,0-}$ 6,8 ( Pracaya, 2003 ).

Kondisi tanah Ultisol dapat diperbaiki dengan memberikan bahan organik. Sehingga tanah tersebut dapat dimanfaatkan untuk proses budidaya tanaman. Bahan organik yang diberikan dapat berupa padatan maupun berupa larutan, namun tujuan utama penambahan bahan organik ke tanah Ultisol adalah untuk memperbaiki sifat fisik, kimia dan biologi tanah tersebut.

Salah satu pupuk organik yang dapat digunakan adalah pupuk organik Super Natural Nutrition ( $\mathrm{SNN})$ yang merupakan pupuk organik cair dan sangat efektif dalam penggunaannya dan dapat menghemat penggunaan pupuk anorganik. Pupuk organik ( SNN ) merupakan ekstraksi bahan organik limbah ternak, limbah tanaman dan limbah alam yang diproses dengan tetap mengutamakan teknologi berwawasan lingkungan, mengandung bahan organik hara esensial makro dan mikro yang 
diperlukan oleh tanaman seperti $\mathrm{N}$, $\mathrm{P}, \mathrm{KMg}, \mathrm{S}, \mathrm{Ca}, \mathrm{Fe}, \mathrm{Na}, \mathrm{Zn}, \mathrm{Cu}, \mathrm{Mn}$, $\mathrm{B}, \mathrm{Cl}$, yang memenuhi kebutuhan tanaman dalam pertumbuhannya. SNN juga dapat meningkatkan $\mathrm{pH}$ tanah dan mampu megurangi tigkat serangan hama serta menghancurkan

\section{METODE PENELITIAN}

Penelitian dilaksanakan di Kebun Percobaan Fakultas Pertanian Universitas Lancang Kuning, dengan ketinggian tempat $8 \mathrm{~m} \mathrm{dpl}$, jenis tanah Ultisol.

Penelitian ini dilaksanakan secara eksperimen, dengan menggunakan rancangan lingkungan Acak Lengkap, dan perlakuan yang diberikan ke media tanam adalah pupuk organik SNN yang terdiri dari 6 taraf perlakuan dan tiga kali

Dimana ;

$$
y=\beta_{0}+\beta_{1} x+\beta_{2} x^{2} \quad \text { ( sumber : Gomez and Gomez, 1995) }
$$

$\mathrm{y}=$ hasil pengamatan

$\beta_{0}=$ hasil yang sesungguhnya bila tidak memakai pupuk SNN

$\beta_{1}=$ koefisien arah garis regresi

$\mathrm{x}=$ dosis pupuk

Benih selada yang digunakan direndam dalam air selama 1 jam, kemudian disemaikan di kotak persemaian yang sudah disediakan dengan perbandingan media semai 2 bagian tanah 1 bagian pupuk kandang. Pesemian dinaungi dengan anyaman daun kelapa untuk menghindari terpaan air hujan.

Semaian yang berumur dua minggu dipindahkan ke plot percobaan yang sudah disiapkan, dengan ukuran plot $60 \times 60 \mathrm{~cm}$ dan tinggi $20 \mathrm{~cm}$, jarak antar plot $50 \mathrm{~cm}$. bibit selada berdauin tiga, ditanam dengan jarak tanah $30 \mathrm{~cm}$ x $30 \mathrm{~cm}$. residu pupuk anorganik ( Indmira, 1999 ).

Tujuan penelitian ini adalah untuk mendapatkan konsentrasi pupuk organik SNN yang optimum yang menghasilkan produksi terbaik pada tanaman selada.

ulangan. Perlakuan yang dimaksud adalah :

$\mathrm{S}_{0} \quad=$ tanpa pupuk SNN

$\mathrm{S}_{1} \quad=\mathrm{SNN} 0,5 \mathrm{cc} / 1$ air

$\mathrm{S}_{2}=\mathrm{SNN} 1 \mathrm{cc} / 1$ air

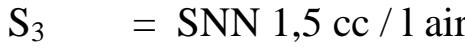

$\mathrm{S}_{4} \quad=$ SNN $2 \mathrm{cc} / 1$ air

$\mathrm{S}_{5} \quad=\mathrm{SNN} 2,5 \mathrm{cc} / 1$ air.

Untuk mendapatkan konsentrasi optimum dalam penggunaan pupuk SNN, maka digunakan analisis regresi polynomial dengan model sebagai berikut :

Perlakuan pupukorganik SNN diberikan dua kali yaitu (1) pada saat pengolahan tanah yang kedua, dan (2) pada saat tanaman berumur 10 hari setelah pindah tanam, dan untuk kontrol pupuk Urea dan TSP diberikan dengan waktu pemberian yang sama dan jumlah yang sama. Caranya SNN dilarutkan dalam air sesuai dengan konsentrasi perlakuan, dan disiramkan ke tanah / plot dengan jumlah penyiraman yang sama.

Pemeliharaan tanaman meliputi; penyiraman pagi dan sore hari dengan jumlah air yang sama, pemupukan; pupuk yang digunakan adalah TSP $5 \mathrm{~g}$ dan Urea $5 \mathrm{~g}$, dengan cara dilarutkan dalam air bersama SNN dan diberikan pada saat perlakuan SNN yang kedua. Penyiangan dilakukan secara manual, dan sekaligus dilakukan 
penggemburan tanah, pada tanaman yang berumur 15 hari setelah pindah tanam.

Panen dilakukan pada saat daun bagian bawah hampir menyentuh tanah.

\section{HASIL DAN PEMBAHASAN}

Hasil penelitian menunjukkan bahwa Tinggi tanaman, Jumlah daun, dan Panjang daun tanaman selada meningkat dengan meningkatnya konsentrasi pupuk SNN yang diberikan ke media tanam, namun garis regresi menurun pada konsentrasi $2 \mathrm{cc} / \mathrm{l}$ air. Untuk parameter Tinggi tanaman garis regresi mengikuti persamaan garis y $=24.053+5.0046 \mathrm{x}-1.3836 \mathrm{x}^{2}$, dengan nilai $\mathrm{R}^{2}=95.69 \%$, yang berarti bahwa hubungan antara konsentrasi pupuk SNN dengan tinggi tanaman selada erat sekali. Konsentrasi pupuk SN optimum untuk parameter tinggi tanaman
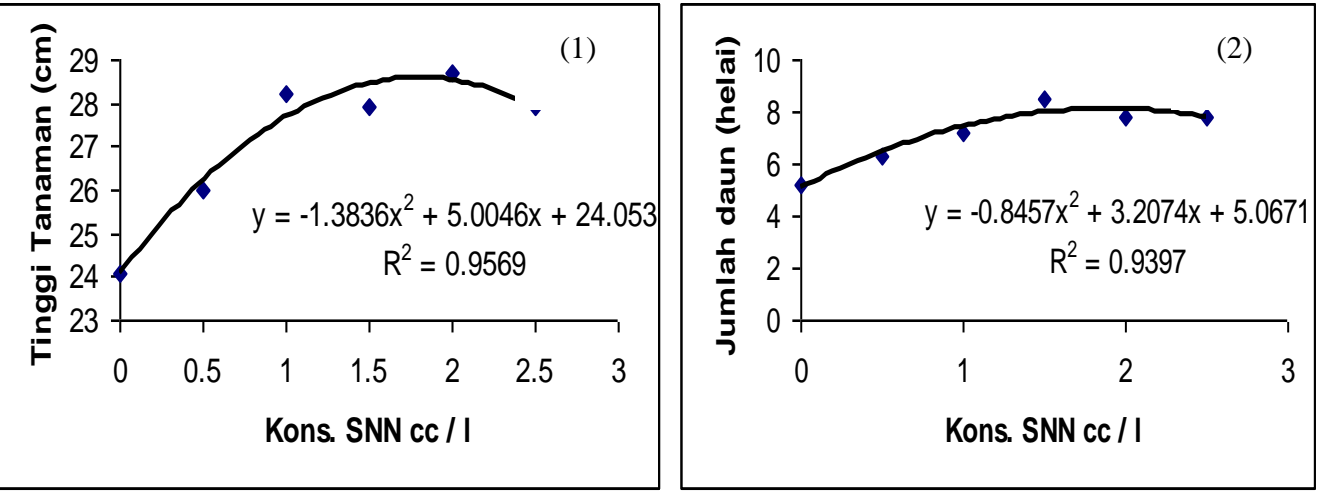

Gambar 1. Kurva hubungan antara konsentrasi pupuk SNN dengan tinggi tanaman selada.

Gambar 2. Kurva hubungan antara konsentrasi pupuk SNN dengan jumlah daun tanaman selada. adalah $1.8 \mathrm{cc} / 1$ air dengan tinggi tanaman mencapai $28.59 \mathrm{~cm}$.

Parameter Jumlah daun mengikuti garis regresi $\mathrm{y}=5.0671+$ $3.2074 \mathrm{x}-0.8457 \mathrm{x}^{2}$, dengan nilai $\mathrm{R}^{2}$ $=93.97 \%$, konsentrasi optimum pupuk SNN adalah $1.9 \mathrm{cc} / 1$ degan jumlah daun sebanyak 8.11 helai.

Panjang daun selada digambarkan berdasarkan persamaan garis regresi $\mathrm{y}=12.319+1.451 \mathrm{x}-$ $0.4 \mathrm{x}^{2}$, dengan nila $\mathrm{R}^{2}=73.01 \%$, konsentrasi optimum untuk menghasilkan panjang daun selada adalah $1.8 \mathrm{cc} / 1$ dengan panjang daun $13.65 \mathrm{~cm}$. 

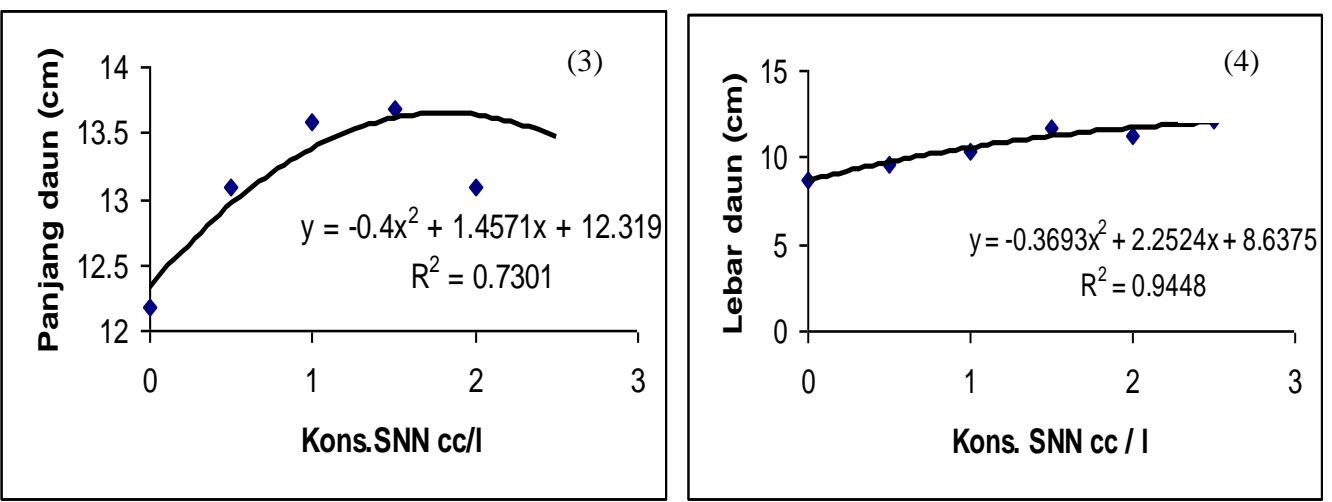

Gambar 3. Kurva hubungan antara konsentrasi pupuk SNN dengan panjang daun tanaman selada.

Gambar 4.Kurva hubungan antara konsentrasi pupuk SNN dengan lebar daun tanaman selada.

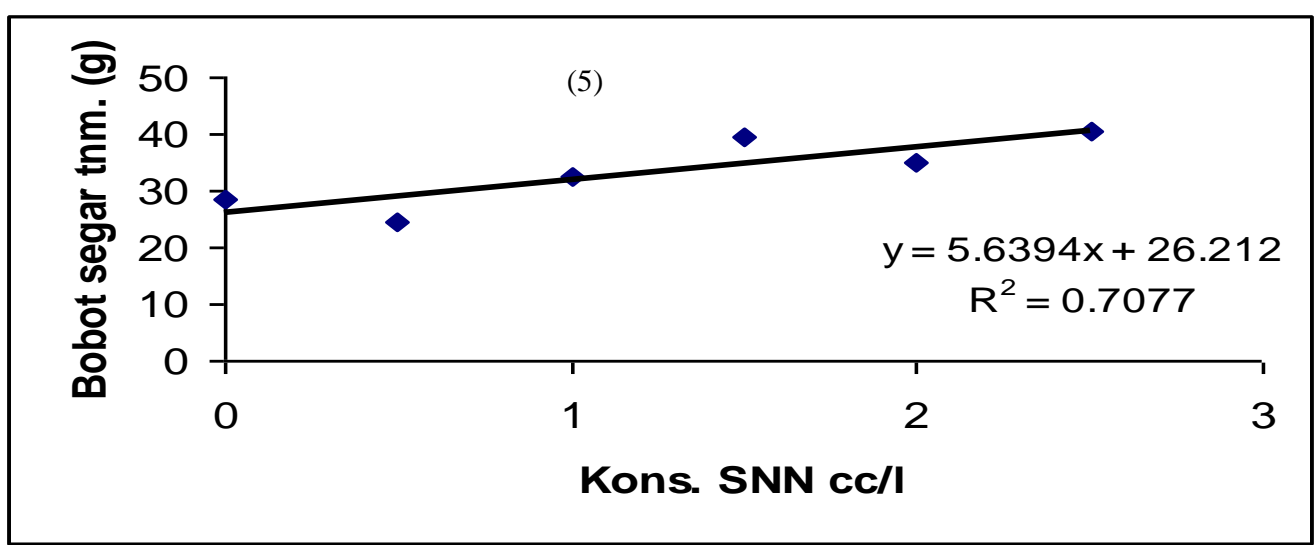

Gambar 5. Kurva hubungan antara konsentrasi pupuk SNN dengan bobot segar tanaman selada.

Gambar 4. menggambarkan tentang lebar daun tanaman selada berdasarkan garis regresi y $=8.6375$ $+2.2524 \mathrm{x}-0.3693 \mathrm{x}^{2}$ dan $\mathrm{R}^{2}=$ $94.48 \%$. Hal ini berarti bahwa lebar daun selada sangat erat hubungannya dengan konsentrasi pupuk SNN, dari Gambar 4. di atas terlihat semakin tinggi konsentrasi pupuk SNN maka semakin lebar daun yang dihasilkan. Titik optimum konsentrasi pupuk SNN untuk parameter lebar daun adalah 2.5 cc / 1 air yang memberikan lebar daun $11.96 \mathrm{~cm}$.

Gambar 5. memperlihatkan bobot segar tanaman, dimana semakin tinggi konsentrasi pupuk
SNN maka semakin tinggi bobot segar tanaman selada. Dari persamaan garis regresi diperlihatkan hubungan yang linier antara konsentrasi pupuk SN dengan bobot segar tanaman selada, garis regresi tersebut berdasarkan persamaan $\mathrm{y}=$ $26.212+5.639 \mathrm{x}$, dengan $\mathrm{R}^{2}=70.77$ $\%$. Bila dilihat dari bentuk garis maka kecendrungan bobot segar tanaman akan semakin besar bila konsentrasi pupuk SNN ditingkatkan. Pada parameter bobot segar tanaman selada titik optimum penggunaan pupuk adalah $2.5 \mathrm{cc} / 1$ air dengan bobot segar tanaman $40.32 \mathrm{~g} /$ tanaman. 
Konsentrasi optimum untuk parameter tinggi tanaman, jumlah daun, dan panjang daun adalah $1.8 \mathrm{cc}$ / 1 air sampai 1.9 cc / 1 air, pada konsentrasi tersebut sudah mampu untuk meningkatkan tinggi tanaman, jumlah daun, dan panjang daun. Dan itu merupakan konsentrasi terbaik untuk ketiga parameter tersebut. Konsentrasi yang lebih tinggi tidak mampu meningkatkan tinggi tanaman, jumlah daun, dan panjang daun tanaman selada. Justru terjadi penurunan tinggi tanaman, jumlah daun, dan panjang daun. Hal ini disebabkan karena faktor genetik dari tanaman selada lebih dominan dibandingkan faktor lingkungannya dalam memacu pertumbuhan tinggi tanaman, jumlah daun, dan panjang daunnya.

Sedangkan untuk parameter lebar daun dan bobot segar tanaman selada maka konsentrasi optimum pupuk SNN adalah $2.5 \mathrm{cc} / 1$ air. Produksi selada sangat ditentukan oleh bobot segar tanaman, oleh karena itu pada penelitian ini konsentrasi $2.5 \mathrm{cc} / 1$ air merupakan konsentrasi yang paling tepat dalam meningkatkan produksi selada di Kota Pekanbaru.

Pada konsentrasi $2.5 \mathrm{cc} / 1$ air dianggap mampu meningkatkan kekurangan unsur hara pada tanah Ultisol, dan mampu memperbaiki kondisi fisik tanah Ultisol menjadi lebih baik, dan mampu menggiatkan aktifitas mikroorganisme yang ada pada tanah tersebut, sehingga kebutuhan hara yang diperlukan tanaman selada dapat terpenuhi. Salah satu fungsi pupuk SNN adalah mampu menghancurkan residu pupuk anorganik. Akibatnya unsur hara yang tersedia dalam media tanam dapat diserap dan dimanfaatkan oleh tanaman untuk memenuhi kebutuhan hidupnya.

Unsur hara yang terkandung dalam pupuk SNN baik makro maupun mikro, seperti $\mathrm{N}, \mathrm{P}, \mathrm{K}, \mathrm{Mg}$, $\mathrm{S}, \mathrm{Ca}, \mathrm{Fe}, \mathrm{Zn}, \mathrm{B}$, dan yang lainnya berperan dalam membantu proses metabolisme tanaman. ( Merchner , 1995 ; Goldwin dan Merchner, 1983, dalam Mutryarny, 2007 ) menyatakan bahwa nutrisi dan mineral yang ada dan tersedia bagi tanaman, terutama $\mathrm{N}$ memiliki pengaruh yang paling menonjol terhadap pertumbuhan dan perkembangan tanaman karena dapat meningkatkan Fitohormon Sitokinin, sebaliknya Sitokinin berperan untuk meningkatkan serapan $\mathrm{N}$ yang tersedia sehingga dapat mempengaruhi bentuk dan ukuran daun.

Fosfor dan Kalium memiliki peranan penting dalam proses metabolisme tanaman. Fosfor meyebabkan metabolisme berjalan baik dan lancar yang mengakibatkan pembelahan sel, pembesaran sel, dan diferensiasi sel, berjalan lancar. Begitu juga Kalium berperan sebagai aktifator dari berbagai enzim yang penting dalam reaksi fotosintesis dan respirasi, sehingga dapat mengatur serta memelihara potensial osmotik dan pengambilan air yang mempunyai pengaruh positif terhadap penutupan dan pembuksan stomata ( Gardner et al, 991 ).

Novizan ( 2005 ) menyatakan bahwa ketersediaan unsur hara yang dapat diserap tanaman merupakan salah satu faktor yang dapat mempengaruhi tingkat pertumbuhan dan perkembangan tanaman. Unsur Ca sangat dibutuhkan untuk memacu pembelahan sel secara normal dan mengaktifkan sistem enzim tertentu, sehingga terbentuk sel-sel baru pada 
fase vegetatif, sedangkan Boron dibutuhkan tanaman untuk proses diferensiasi sel yang sedang tumbuh.

Pada penelitian ini pupuk anorganik yang diberikan adalah Urea dan TSP masing - masing $5 \mathrm{~g}$, dan diberikan pada saat tanaman berumur 10 hari setelah tanam. Pada kondisi tanpa pemupukan SNN, terlihat bahwa seluruh parameter pengamatan memperlihatkan hasil terendah. Hal ini menggambarkan bahwa fungsi SNN benar - benar dapat membantu perakaran tanaman dalam menyerap unsur hara yang ada

\section{SIMPULAN DAN SARAN}

Simpulan dari penelitian ini adalah konsentrasi optimum pupuk organik SNN adalah $2.5 \mathrm{cc} / 1$ air yang menghasilkan bobot segar tanaman selada yang tertinggi yaitu $40.31 \mathrm{~g} /$ tanaman.

Saran yang diajurkan adalah untuk melakukan penelitian dengan konsentrasi yang lebih tinggi lagi.

\section{DAFTAR PUSTAKA}

Asiamaya 2005. Kandungan Nutrisi daun selada. http://www.asiaaya.com/nutri ent/selada.htm.

Gardner, F.P, R. B. Pearce dan R.L. Mitchell, 1991. Physiologicy ofCrop Plants. Terjemahan HeawatiSuslo. Fisiologi Tanaman Budidaya. Universitas Indonesia.

Gomez. K.A. dan A.A. Gomez 1995. Prosedur statistik untuk penelitian pertanian. Alih bahasa : Syamsudin, E., Baharsyah, J. Universitas Indoesia. di media tanamnya. Dari Gambar gambar tersebut memperlihatkan bahwa pupuk Urea dan TSP yang diberikan tidak berperan aktif dalam meningkatkan pertumbuhan dan produksi tanaman selada, dari hal tersebut jelaslah sudah bahwa pupuk anorganik yang diberikan pada tanah Ultisol bila tidak diikuti dengan pemberian pupuk SNN maka tidak berarti dalam meningkatkan perumbuhan dan produksi tanaman selada.

Indmira 1999. Pupuk Organik Super Natural Nutrition. Brosur. Yogyakarta.

Mutryarny, E. 2007. Respon tanaman jagung ( Zea mays) akibat aplikasi konsentrasi pupuk fitomic dan dosis bokashi pupuk kandang pada tanah PMK. 3: 2 J. Ilmiah Pertanian : $7-16$.

Novizan 2005. Pemupukan yang efektif. Agromeia Pustaka. Jakarta.

Pracaya 2003. Bertanam Sayuran Organik di Kebun, Pot, dan Polybag. Penebar Swadaya. Jakarta.

Surtinah 2006. Peranan Plant
Catalyst2006
meningkakan produksi sawi (
Brassica juncea, L). 3: $1 \mathrm{~J}$.
Ilmiah Pertanian : $6-16$.

